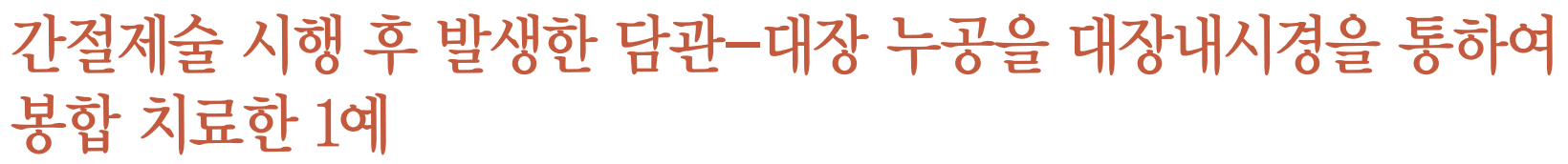

울산대학교 의과대학 서울아산병원 내과

노수민 · 소훈섭 · 신승환 · 양동훈 · 박도현

\title{
Biliary-Colonic Fistula after Hepatectomy Treated by Colonoscopic Clipping
}

Soo Min Noh, Hoonsub So, Seung Whan Shin, Dong-Hoon Yang, Do Hyun Park

Department of Internal Medicine, Asan Medical Center, University of Ulsan College of Medicine, Seoul, Korea

Biliary-colonic fistula is a rare complication after hepatic resection. We present at a case of asymptomatic biliary-colonic fistula that developed 6 months after hepatectomy in a 73-year old female patient. She had been undergoing endoscopic treatment for a postoperative bile leakage, and the fistula was found by follow-up endoscopic retrograde cholangiopancreatography (ERCP). The fistula was formed between the right posterior segmental duct and the colon, and it was closed by colonoscopic clipping under fluoroscopic guidance. There was no recurrence at the 6-week follow-up ERCP.

Korean J Pancreas Biliary Tract 2018;23(1):36-40

\author{
Received Jun. 28, 2017 \\ Revised Aug. 26, 2017 \\ Accepted Sep. 8, 2017
}

Corresponding author : Do Hyun Park

Division of Gastroenterology, Department of Internal Medicine, Asan Medical Center, University of Ulsan College of Medicine, 88 Olympic-ro 43-gil, Songpagu, Seoul 05505, Korea

Tel. +82-2-3010-3194 Fax. +82-2-476-0824

E-mail; dhpark@amc.seoul.kr

Keywords: Fistula, Hepatectomy, Colonoscopy

This is an Open Access article distributed under the terms of the Creative Commons Attribution Non-Commercial License (http:// creativecommons.org/licenses/by-nc/3.0/) which permits unrestricted non-commercial use, distribution, and reproduction in any medium, provided the original work is properly cited

Copyright $\odot 2018$ by The Korean Journal of Pancreas and Biliary Tract
서 론

담관-장관 누공은 담도와 장관 사이에 비정상인 통로가 생 기는 것으로 담도 질환에서 매우 드물게 나타나는 합병증이 다. ${ }^{1}$ 담관-장관 누공은 대부분 담석에 의하여 발생하며 대장 게실, 복부 외상 등에 의해서도 발생되고, 주로 담낭 십이지장 누공의 형태로 나타난다. ${ }^{2,3}$ 수술에 의한 담관-장관 누공 합병 증은 $0.15-4.8 \%$ 정도로 알려져 있다. ${ }^{4}$ 보존적 치료에 반응하지
않을 경우, 수술을 통한 담도전환술(biliary diversion)이 치료 로 알려져 있다. ${ }^{5}$ 저자들은 고분화성 이형성 결절(high-grade dysplastic nodule)에 대해 간우전엽절제술을 시행한 후 발생 한 담즙종에 대하여 보존적 치료 중 내시경적 역행성 췌담도 조영술(endoscopic retrograde cholangiopancreatography, $\mathrm{ERCP})$ 을 통하여 우연히 담관-대장 누공을 발견하였고, 대장 내시경을 통하여 봉합 치료를 한 1 예를 보고하고자 한다. 


\section{증 례}

73세 여자가 소화불량을 주소로 본원 방문하여 non-B, non$\mathrm{C}$ 간경화 및 간우엽에 $2 \mathrm{~cm}$ 크기의 종양이 확인되었다. 환자 는 고혈압, 당뇨로 투약 중이었고, 10년전 뇌경색 및 40년 전 맹장 수술, 자궁적출 수술의 과거력이 있으며 음주력, 흡연력 은 없었다. 가족력으로 어머니가 간경변 및 간암 과거력이 있 었다. 간우전엽절제술과 담낭절제술을 시행하였고, 수술 중
시행한 담도 조영술에서는 총담관의 조영제 누출은 없었다. 병리 결과 고분화성 이형성 결절이 확인되었다. 수술 7일째 간절제면에 위치시킨 배액관(Jackson-Pratt drain)으로 담즙 양상의 배액이 증가하여, $\mathrm{ERCP}$ 를 시행하였으며 문합부 담즙 누출(Fig. 1A)이 확인되어 내시경 유두괄약근절개술(endoscopic sphincterotomy)과 내시경비담관배액술(endoscopic nasobiliary drainage, ENBD)을 시행하였다. 이후 복부 컴퓨 터단층촬영(computer tomography, CT)에서(Fig. 1B) 간 주
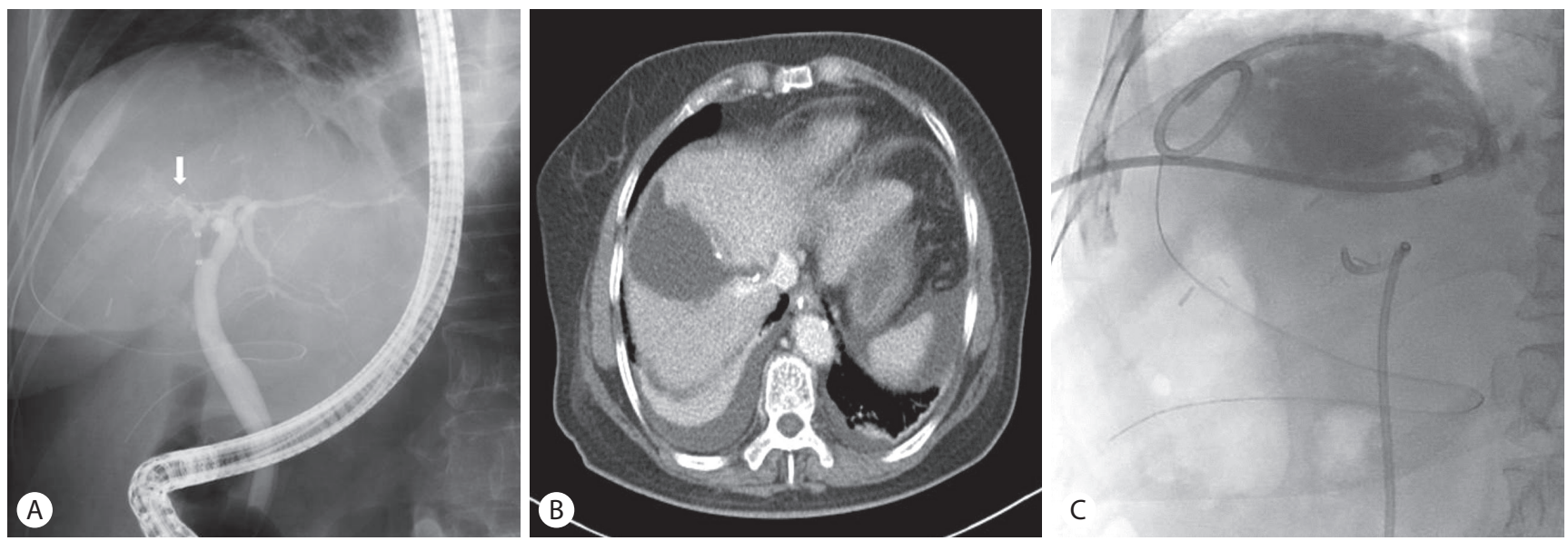

Fig. 1. (A) ERCP revealed bile leak (white arrow) from the stump. (B) Computed tomography showed increased perihepatic fluid collection in spite of endoscopic sphincterotomy and ENBD insertion. (C) Percutaneous abscess drainage tube (8.5 Fr) was inserted for drainage of perihepatic fluid collection. ERCP, endoscopic retrograde cholangiopancreatography; ENBD, endoscopic nasobiliary drainage.
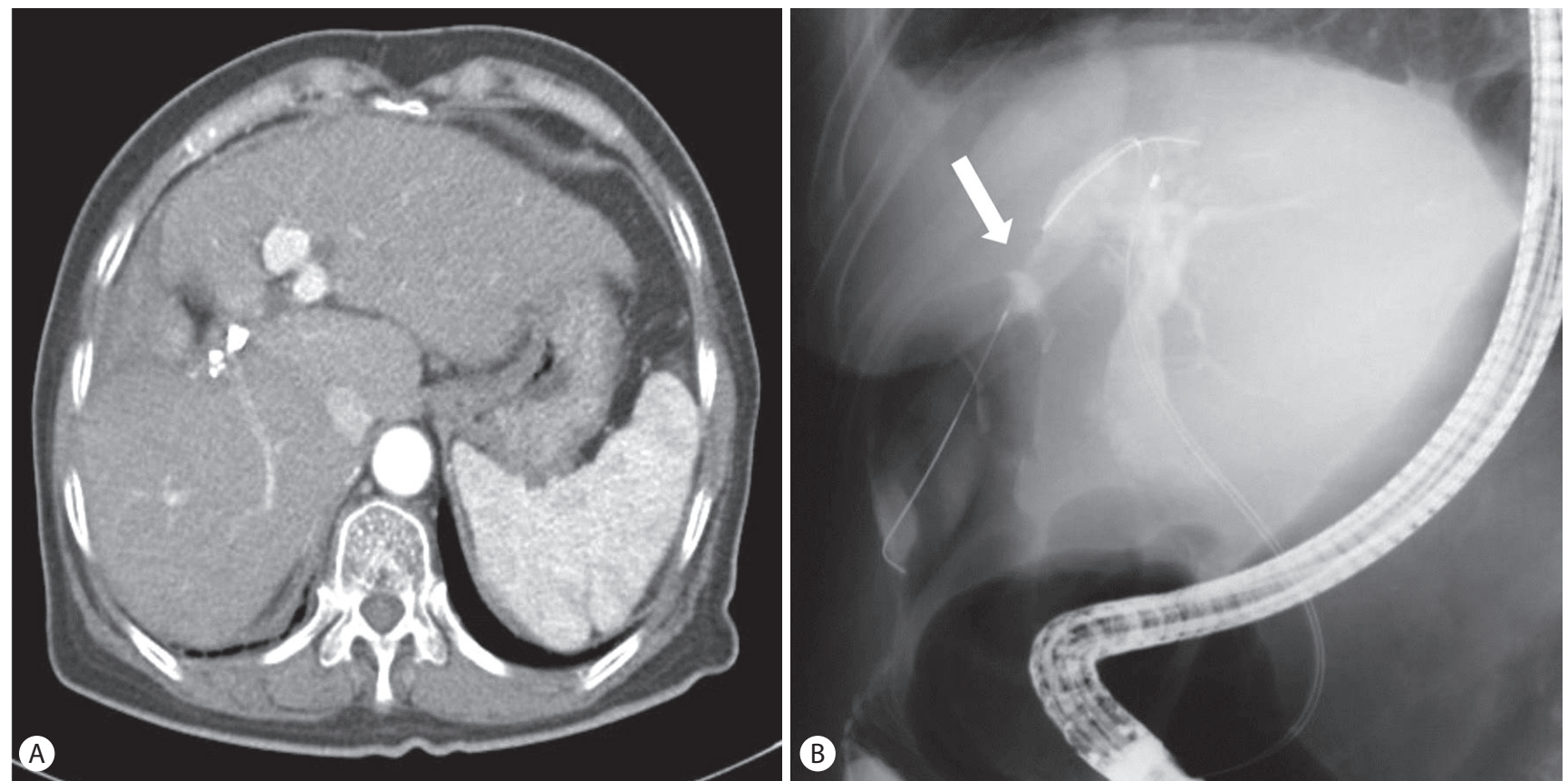

Fig. 2. (A) Computed tomography showed nearly disappeared loculated fluid collection around liver resection margin. (B) Endoscopic retrograde cholangiopancreatography revealed newly developed extravasation of dye from intrahepatic duct to the hepatic flexure of the colon and a guidewire (white arrow) was able to pass through the fistula. 
변부 액체 저류가 지속되었고 $\mathrm{ERCP}$ 를 시행하여 우후분절관 (Rt. posterior segmental duct, RPSD)에 플라스틱 스텐트(7 $\mathrm{Fr})$ 를 삽입하였으나 호전 없이 담즙종이 지속되어 수술 26일 째 복강내 카테터(8.5 Fr)를 삽입하였다(Fig. 1C). 이후 담즙 종은 호전되는 양상을 보여 RPSD에 금속 스텐트를 삽입하였 으며 수술 8주째 복강내 카테터를 제거 후 퇴원하였다. 이후 수술 20주째 담즙종이 지속되어 플라스틱 스텐트로 교체를 시행하였다.

6주 후(수술 26주 후) 내시경 담관 스텐트를 교체하기 위해 입원하였고, 입원 당시 혈압 $138 / 74 \mathrm{mmHg}$, 맥박 80 회/분, 체 온 $36.6^{\circ} \mathrm{C}$ 였고 계통적 문진에서 발열, 오한 없었으며 신체 검 진에서 특이 사항은 없었다. 검사실 소견에서 백혈구 6,500/ $\mathrm{mm}^{3}$, 호중구 $62.6 \%$ 였으며, C-반응단백 $0.70 \mathrm{mg} / \mathrm{dL}$, 총빌리 루빈 및 직접빌리루빈은 각각 $0.7 \mathrm{mg} / \mathrm{dL}$ 및 $0.4 \mathrm{mg} / \mathrm{dL}$ 로 정 상 소견을 보였다. 복부 CT 시행하였으며 (Fig. 2A) 기존에 플 라스틱 스텐트의 위치는 잘 유지되고 있으며, 이전 보이던 액 체 저류는 대부분 소실된 상태였다. ERCP를 시행하여 이전 에 거치한 플라스틱 스텐트를 제거하였고 담관조영술에서 담 즙종의 크기는 감소한 소견을 보였다. 하지만 총담관에 주입 된 조영제가 대장 간결장곡으로 누출되어 간내담관과 담즙종 그리고 대장 사이에 누공 형성이 의심되었으며, 유도 철사 삽 입시 대장 간결장곡 쪽으로 넘어가 담관-대장 누공이 확인되 었다(Fig. $2 \mathrm{~B}$ ). 이 누공에 대한 내시경 치료를 고려하기로 하고 우선 RPSD에 플라스틱 스텐트(double pig-tail stent 직경/길 이 $7 \mathrm{Fr} / 12 \mathrm{~cm})$ 를 거치하였다.

다음 날 대장내시경을 시행하였고 간결장곡 부위에 담관-대 장 누공이 의심되는 부위가 발견되었으나 전반적으로 주변에 염증 소견은 보이지 않았다(Fig. $3 \mathrm{~A}$ ). 조영제를 사용하였을 때
뚜렷이 누공이 관찰되지 않았으나, X-선 투시경에서 하루 전 $\mathrm{ERCP}$ 에서 관찰되던 부위와 일치한다고 판단되어 클립 4 개 (Long clip, Olympus Optical Co., Ltd., Tokyo, Japan)를 사용하여 누공을 봉합한 후 시술을 종료하였다(Fig. 3B, C). 6 주 후 시행한 ERCP에서 담관-대장 누공 소견은 더 이상 관찰되지 않아 기존 에 삽입되었던 담도 플라스틱 스텐트는 제거하였다(Fig. 4).

\section{고 찰}

간절제술 후 담즙 누출은 비교적 흔한 합병증으로 수술한

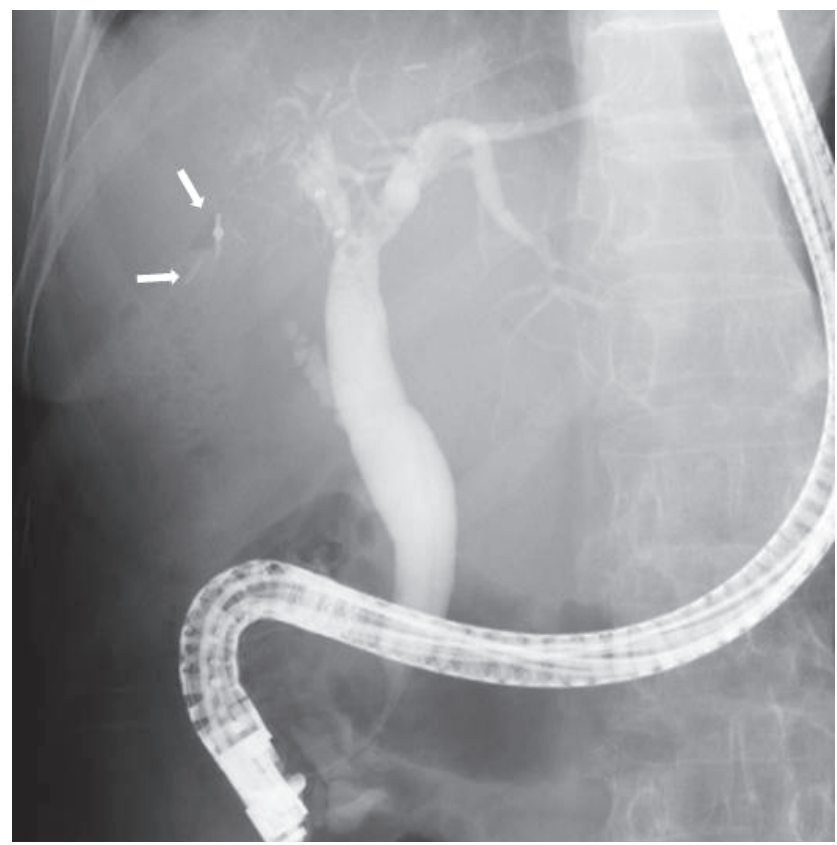

Fig. 4. Six weeks after the clipping, follow-up endoscopic retrograde cholangiopancreatography did not show any evidence of biliary-colonic fistula. The previously placed clips were observed (white arrows).
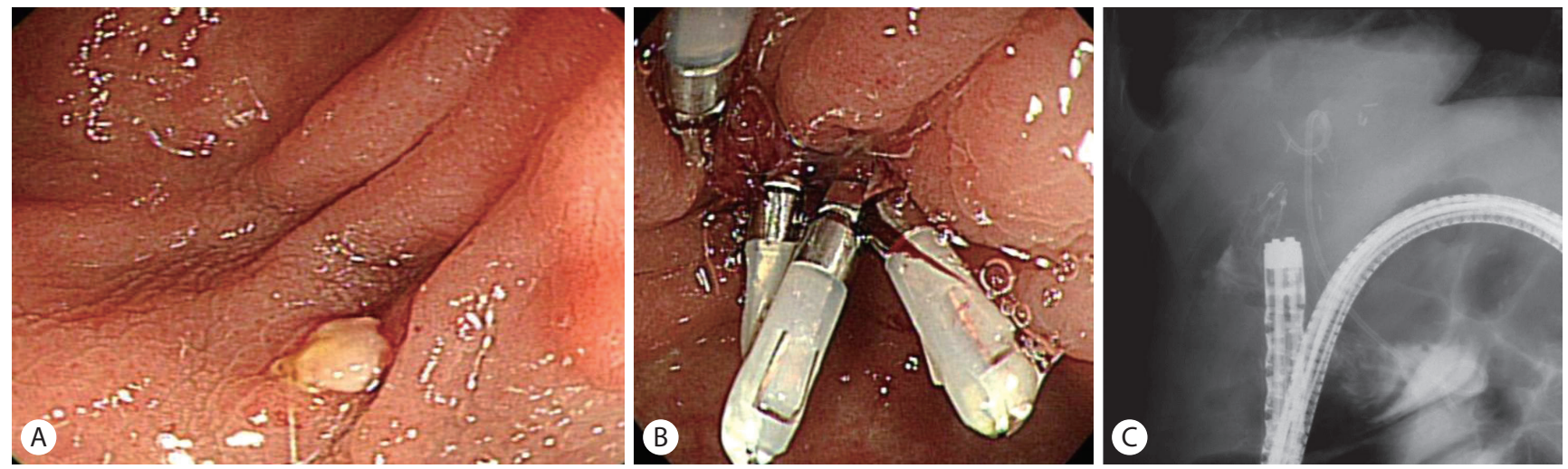

Fig. 3. (A) Endoscopic image showing suspicious opening of the biliary-colonic fistula. (B) Biliary-colonic fistula was closed by using four clips. (C) Fluoroscopic image during colonoscopic clipping. 
환자에서 2.5-12\%까지 발생할 수 있다고 알려져 있다..$^{6-9}$ 담즙 이 누출되어 형성된 담즙종은 위치 및 피막형성에 관계없이 담도 밖에서 담즙이 모여 경계를 이룬 것을 지칭하는 것으로 ${ }^{10}$ 크기가 크지 않고 무증상일 경우 다른 처치 없이 자발 회복이 가능하나 크기가 크거나 증상이 있을 경우 경피간담관조영술 (percutaneous transhepatic cholangiography, PTC) 또는 $\mathrm{ERCP}$ 를 통하여 해부학적 구조를 확인한 후 적절한 배액술을 통하여 수술적 치료를 피할 수 있다. 본 증례에서도 간우전엽 절제술 후 7일째 담즙 양상으로 경피적 배액량 늘어나 담도 손상이 의심되어 $\mathrm{ERCP}$ 를 통해 유두괄약근절개술과 $\mathrm{ENBD}$ 를 삽입하였다. 이후에도 배액량이 줄지 않아 다시 시행한 $\mathrm{ERCP}$ 에서 담즙종 확인되어 복부 배액관을 1 달 동안 거치하 였다. 이후 담즙종은 호전과 악화를 반복하였고, 수술 4 개월 후 시행한 ERCP에서는 누공을 의심할 만한 소견은 없었다.

담관-장관 누공은 매우 드물게 나타나는 합병증으로 담관장관 누공은 대부분 담관결석에 의하여 발생하며 대장 게실, 복부 외상, 염증성 장질환, ${ }^{11}$ 간 디스토마 ${ }^{12}$ 의해서도 발생되는 것으로 보고하고 있다. 이차적 담관-장관 누공은 담도의 미란 과 손상 그리고 기계적 폐쇄로 인한 담도내 압력 상승으로 담 도내 결석과 궤사 조직들이 쌓이게 되고 이것이 장까지 침범 하게 되어 누공이 생긴다고 설명하고 있다. ${ }^{13}$ 또한 수술 관련 하여서는 간이식, 담도공장문합술, 담낭절제술 이후 담도 손 상으로 인한 담관 누공 보고가 있다. ${ }^{5}$

본 증례의 경우는 간부분절제술 및 담낭절제술을 받았던 환자로 수술 이후 오랜 기간 동안 담즙종이 지속된 것으로 미 루어 보아 담관 내의 압력 상승과 감염으로 인한 담도벽의 약 화 및 궤사로 인하여 담관-담즙종-대장 누공이 형성된 것으로 추정된다.

Macedo 등 ${ }^{5}$ 은 담낭절제술 후 발생한 담관-대장 누공을 자 기공명췌담도조영술(magnetic resonance cholangiopancreatography)과 PTC 통해 확인하여 담관-대장 누공을 우선 외 부 배액관을 통하여 풍선으로 확장시킨 후, 1 달 후 개복하여 누공 부위 장절제 및 담도 재복원술을 통하여 환자를 호전시 킨 증례를 보고하였다. Munene 등 $^{13}$ 도 개복 담낭절제술을 시 행하였던 환자가 4 개월 후 황달 주소로 내원하여 경피적 담 관조영술을 통하여 담관-대장 누공을 확인하여 누공 부위 장 절제 및 Roux-en-Y 문합 수술을 통하여 치료한 증례를 보고 하였다. 국내에도 간세포암으로 고주파열 치료(radiofrequency ablation)를 시행한 후 간농양벽의 괴사로 간대장누
공이 발생한 환자에서 먼저 내시경적인 처치로 클립봉합술을 시도하였으나 실패하여 복강경 통하여 누공절제술 및 상행 결장 쐐기절제술을 시행한 보고가 있다. ${ }^{14}$ 담즙 누출에 대한 치료는 내시경 유두괄약근절개술과 담관내로 스텐트 삽입이 널리 사용되는 방법으로 특별한 경우를 제외하고 담즙 누출 원인에 관계없이 내시경 치료성공률은 91-95\%로 안전하고 성공적인 것으로 알려져 있다. ${ }^{12}$ 반면에 담관-대장누공에 대 한 치료는 간공장문합술과 Hutson-Russell 방법을 통한 담도 를 재복원하는 것으로 알려져 있다. ${ }^{5}$ 하지만 본 증례는 내원 6 주 전 $\mathrm{ERCP}$ 에서 관찰되지 않던 담관-대장 누공이 확인된 경 우로, 형성된 지 얼마 되지 않았고, 감염의 징후가 없으며 누 공 주변으로 섬유화가 심하지 않아 우선 대장내시경으로 봉 합을 시도하였다. 위장관 누공과 누출 치료에 효과적으로 알 려져 있는 Over-the-scope Clip 사용이 본 증례에서도 적용 가능하였다. ${ }^{15}$ 그러나 고가이면서 국내에서는 급여 적용되지 않아 본 환자에서는 지혈용 클립을 사용하였다. 당시 육안상 누공이 뚜렷하지는 않았지만 X-선 투시경의 도움을 받아 시 술을 시행하였고, 6주 후 담도조영술을 시행한 결과 담관에 서 대장으로의 조영제의 누출이 더 이상 관찰되지 않았다. 결 론적으로 본 증례는 반복적인 스텐트 삽입을 통한 담도 배액 술에도 불구하고 지속되는 담즙종에 의하여 발생한 담관-대 장 누공을 대장 클립 거치를 통해 비침습적이고 안전하게 내 시경적으로 치료한 경우이다. 본 증례와 같이 담도 배액술을 위한 조영술 과정에서 우연히 발견되고, 경과가 오래되지 않 은 담관-대장 누공은 내시경 대장 클립거치만으로도 치료가 가능하므로 이러한 환자군에서는 보다 세심한 담도 조영술 촬영이 필요하다고 생각된다.

\section{요 약}

간절제술 후 담관-대장 누공은 매우 드물게 나타나는 합병 증으로 알려져 있다. 저자들은 73세 여성에서 간절제술을 시 행한 후 발생한 담즙종에 대하여 반복적인 담도 배액술 치료 중 내시경적 역행성 췌담도 조영술을 통하여 우연히 담관-대 장 누공을 발견하였고, 이를 내시경적으로 대장 클립 거치를 통하여 치료에 성공하였던 1 예를 경험하였기에 문헌고찰과 함께 보고하고자 한다.

국문 색인: 담관-대장 누공, 간절제술, 대장내시경 


\section{Conflicts of Interest}

The authors have no conflicts to disclose.

\section{REFERENCES}

1. Yamashita H, Chijiiwa K, Ogawa Y, Kuroki S, Tanaka M. The internal biliary fistula-reappraisal of incidence, type, diagnosis and management of 33 consecutive cases. HPB Surg 1997;10:143-147.

2. Guitrón-Cantú A, Adalid-Martínez R, Barinagarrementeria-Aldatz $R$, Carrillo-Maciel V, Gutiérrez-Bermudez JA, Meza-Mata E. Choledochocolonic fistula secondary to primary choledocholithiasis. Gastrointest Endosc 2001;54:227.

3. Benson AJ, Reinschmidt J, Billingsley JL, Timmons JH, Parish GH. Biliary-colonic fistula diagnosed via hepatobiliary scintigraphy. Clin Nucl Med 2001;26:150-151

4. Chowbey PK, Bandyopadhyay SK, Sharma A, Khullar R, Soni V, Baijal M. Laparoscopic management of cholecystoenteric fistulas. J Laparoendosc Adv Surg Tech A 2006;16:467-472.

5. Macedo Fl, Casillas VJ, Davis JS, Levi JU, Sleeman D. Biliary-colonic fistula caused by cholecystectomy bile duct injury. Hepatobiliary Pancreat Dis Int 2013;12:443-445.

6. Imamura H, Seyama Y, Kokudo N, et al. One thousand fifty-six hepatectomies without mortality in 8 years. Arch Surg 2003;138:1198-1206; discussion 1206

7. Jarnagin WR, Gonen M, Fong Y, et al. Improvement in perioperative outcome after hepatic resection: analysis of 1,803 consecutive cases over the past decade. Ann Surg 2002;236:397-406; discussion 406-407.

8. Capussotti L, Ferrero A, Viganò L, Sgotto E, Muratore A, Polastri R. Bile leakage and liver resection: where is the risk? Arch Surg 2006;141:690694; discussion 695.

9. Yamashita Y, Hamatsu T, Rikimaru T, et al. Bile leakage after hepatic resection. Ann Surg 2001;233:45-50.

10. Kuligowska E, Schlesinger A, Miller KB, Lee VW, Grosso D. Bilomas: a new approach to the diagnosis and treatment. Gastrointestinal Radiology 1983;8:237-243.

11. Kantarci M, Fil F, Aydinli B, Atamanalp SS. Colobiliary fistula: a rare complication of Crohn's disease. Wien Klin Wochenschr 2008;120:477.

12. Eun JR, Kim TN, Choi ST, Jang BI. The causes and endoscopic management of bile leak. Korean J Gastrointest Endosc 2006;33:346-352.

13. Munene G, Graham JA, Holt RW, Johnson LB, Marshall HP Jr. Biliary-colonic fistula: a case report and literature review. Am Surg 2006;72:347-350.

14. Kang MG, Lee TH, Na WT, et al. Hepatocolic fistula after radiofrequency ablation for hepatocellular carcinoma. Korean J Med 2012;83:480484.

15. Manta R, Caruso A, Cellini C, et al. Endoscopic management of patients with post-surgical leaks involving the gastrointestinal tract: a large case series. United European Gastroenterol J 2016;4:770-777. 